\title{
Hydration Characteristics and Synthesis of Hauyne-Belite Cement as Low Temperature Sintering Cementitious Materials
}

\author{
Sang-Jin Park*, Se-Hoon Jeon**, Kyung-Nam Kim*, and Myong-Shin Song**; \\ *Department of Advanced Materials Engineering, Kangwon National University, Samcheock 25913, Korea \\ **Research Center of Advanced Convergence Processing on Materials, Kangwon National University, Samcheock 25913, Korea
}

(Received October 23, 2017; Revised March 19, 2018; Accepted March 20, 2018)

\begin{abstract}
OPC production requires high calorific value and emits a large amount of $\mathrm{CO}_{2}$ through decarbonation of limestone, accounting for about $7 \%$ of $\mathrm{CO}_{2}$ emissions. To reduce $\mathrm{CO}_{2}$ emissions during the Ordinary Portland Cement (OPC) production process, there is a method of reducing the consumption of cement or lower temperature calcination for OPC product. In this study, for energy consumption reduction, we prepared Hauyne-belite cement by calcination at a low temperature compared to that used for OPC and studied the early hydration properties of the synthesized Hauyne-belite cement. We set the ratios of Hauyne and belite to $8: 2,5$ $: 5$ and $3: 7$. For the hydration properties of the synthesized Hauyne-belite cement, we tested heat of hydration of paste and the compressive strength of mortar, using XRD and SEM for analysis of hydrates. As for our results, the temperature for optimum synthesis of Hauyne-belite is $1,250^{\circ} \mathrm{C}$. Compressive strength of synthesized Hauyne-belite cement is lower than that of OPC, but it is confirmed that compressive strength of synthesized Hauyne-belite cement with mixing in of some other materials can be similar to that of OPC.
\end{abstract}

Key words : Hauyne, Belite, $\mathrm{CSA}, \mathrm{CO}_{2}$

\section{Introduction}

$\mathrm{C}$ ompared to many industries, the cement industry has high energy consumption due to the high calcination temperature required in the production of clinker. Approximately 0.9 tons of $\mathrm{CO}_{2}$ are produced for each container of cement, and approximately 50 million tons of $\mathrm{CO}_{2}$ are produced in the domestic cement industry. ${ }^{1)}$ Ordinary Portland Cement (OPC) is the most widely used binder for concrete used for construction. As the use of OPC increases, the production of $\mathrm{CO}_{2}$ increases as well and contributes to environmental problems such as global warming. ${ }^{2)}$ There are a number of representative methods that can used to reduce emissions of $\mathrm{CO}_{2}$ and energy in the production of cement, including numerous approaches for low temperature calcination of cement, and geopolymers. Hauyne-Belite cement (HBC) has been reported to be manufacturable at low calcination temperature compared to conventional OPC. Thus, the development of $\mathrm{HBC}$ can reduce the use of natural resources compared to the fabrication of OPC, while reducing energy consumption and $\mathrm{CO}_{2}$ emissions, relieving environmental loads.

HBC produces ettringite through the hydration reactions

\footnotetext{
Corresponding author: Myong-Shin Song

E-mail : msong0422@kangwon.ac.kr

Tel : +82-33-570-6558 Fax : +82-33-570-6556

${ }^{\ddagger}$ Corresponding author: Se-Hoon Jeon

E-mail : zine2421@naver.com

Tel : +82-33-570-6556 Fax : +82-33-570-6556
}

of $\mathrm{CaO}$ and $\mathrm{CaSO}_{4}$ and the hydration product of acicular crystals improves compressive strength by micropore densificiation of the cement hardener. ${ }^{3)}$ Also, it has been reported that belite influences long-term strength. ${ }^{4)}$

In this study, HBC was synthesized at temperatures below the low calcination temperature of $1300^{\circ} \mathrm{C}$, compared to that of conventional OPC, and the properties of HPC were evaluated. Additionally, the initial hydration reaction properties and compressive strength based on various Hauyne and Belite composition ratios were investigated, ${ }^{5)}$ and hydrate analysis was carried out.

\section{Experiment Procedure}

\subsection{Synthesis Materials}

The materials used in the synthesis of HBC were reagent grade, ${ }^{6}$ and Table 1 shows the properties of the reagents used in the synthesis.

\subsection{Optimal HBC Synthesis Condition}

The mixing ratio was determined according to the molar ratio used for the synthesis of HBC. Table 2 shows the synthesis molar ratio where the target ratios of Hauyne and Belite were $8: 2,5: 5$, and $3: 7$.

In order to determine the phase transition temperatures of the Hauyne ${ }^{7}$ and Belite, TG-DTA (Netzsch. Co., STA409PC Luxx model) analysis was conducted. Measurements were carried out up to the maximum temperature of $1,400^{\circ} \mathrm{C}$ with a heating rate of $5^{\circ} \mathrm{C} / \mathrm{min}$, and under $\mathrm{O}_{2}$ atmosphere. Fig. 1 
Table 1. Hauyne-Belite Cement Synthetic Materials

\begin{tabular}{|c|c|c|c|}
\hline Component & Product & $\begin{array}{l}\text { Molecular } \\
\text { weight (g) }\end{array}$ & Purity \\
\hline $\mathrm{CaCO}_{3}$ & DAEJUNG & 100.09 & Extra pure \\
\hline $\mathrm{Al}_{2} \mathrm{O}_{3}$ & JUNSEI & 101.96 & $\begin{array}{c}\text { Guaranteed } \\
\text { Reagent }\end{array}$ \\
\hline $\mathrm{CaSO}_{4}$ & Alfa Aesar & 136.14 & $99 \%$ \\
\hline $\mathrm{SiO}_{2}$ & JUNSEI & 60.08 & Extra pure \\
\hline
\end{tabular}

Table 2. Hauyne-Belite Cement Synthesis Ratio Unit (wt.\%)

\begin{tabular}{cccccc}
\hline $\begin{array}{c}\text { Type } \\
\text { name }\end{array}$ & $\mathrm{CaCO}_{3}$ & $\mathrm{Al}_{2} \mathrm{O}_{3}$ & $\mathrm{CaSO}_{4}$ & $\mathrm{SiO}_{2}$ & $\mathrm{SUM}$ \\
\hline $\mathrm{HC}$ & 49.9 & 30.5 & 13.6 & 6.0 & 100 \\
$\mathrm{MC}$ & 61.7 & 17.2 & 7.6 & 13.5 & 100 \\
$\mathrm{LC}$ & 63.7 & 10.8 & 4.8 & 17.0 & 100 \\
\hline
\end{tabular}

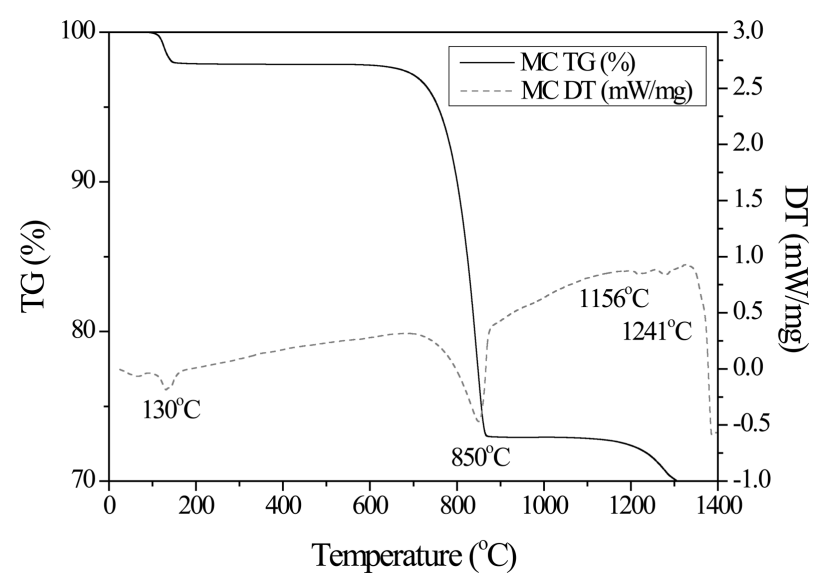

Fig. 1. Results of TG-DTA.

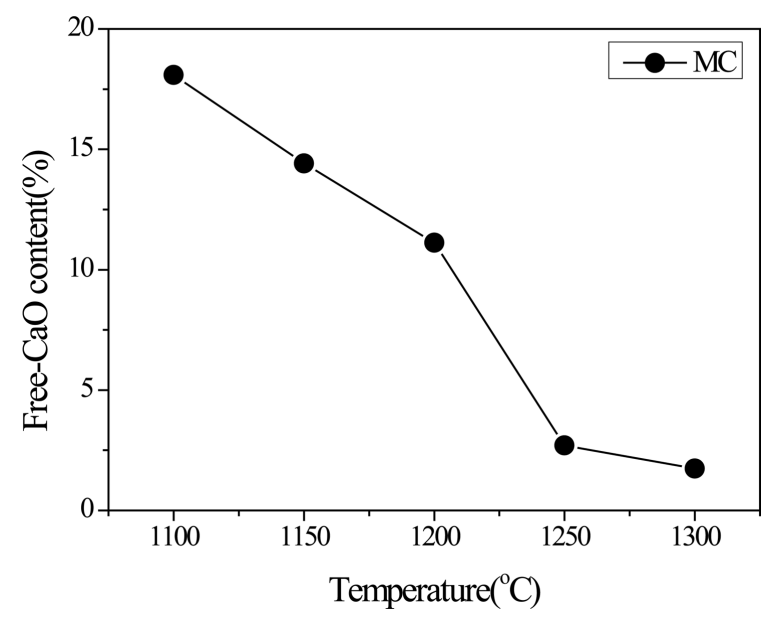

Fig. 2. Results for free-CaO using ethylene glycol.

shows the analysis results.

In addition, the amount of free- $\mathrm{CaO}$ depending on calcination temperature was determined by using the ethylene glycol method. Fig. 2 shows the free-CaO content according to

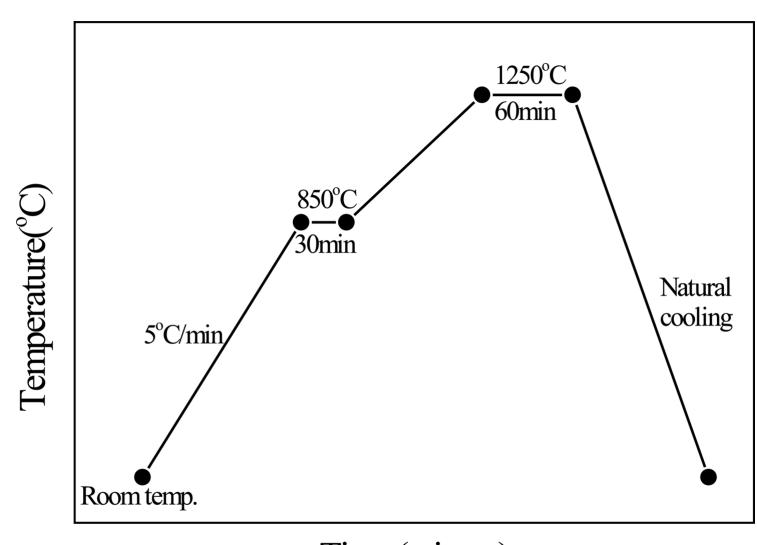

Time (minute)

Fig. 3. Hauyne-Belite Cement firing condition.

Table 3. XRD-Rietveld Product Yield

\begin{tabular}{cccccccc}
\hline & & $\begin{array}{c}\mathrm{CSA} \\
(\%)\end{array}$ & $\begin{array}{c}\mathrm{C}_{2} \mathrm{~S} \\
(\%)\end{array}$ & $\begin{array}{c}\mathrm{CaSO}_{4} \\
(\%)\end{array}$ & $\begin{array}{c}\mathrm{CaO} \\
(\%)\end{array}$ & $\begin{array}{c}\mathrm{Al}_{2} \mathrm{O}_{3} \\
(\%)\end{array}$ & $\begin{array}{c}\text { Etc. } \\
(\%)\end{array}$ \\
\hline \multirow{3}{*}{$1250^{\circ} \mathrm{C}$} & $\mathrm{HC}$ & 84.3 & 15.7 & - & - & - & - \\
& $\mathrm{MC}$ & 46.9 & 53.1 & - & - & - & - \\
& $\mathrm{LC}$ & 31.7 & 68.3 & - & - & - & - \\
\hline
\end{tabular}

temperature. Since free-CaO of around $10 \%$ was present up to $1200^{\circ} \mathrm{C}$, it was determined that the temperature range was not appropriate. The amounts of free- $\mathrm{CaO}$ for $1250^{\circ} \mathrm{C}$ and $1300^{\circ} \mathrm{C}$ were $2.08 \%$ and $1.54 \%$, respectively, so the appropriate temperature range was determined to be $1250^{\circ} \mathrm{C}$ or $1300^{\circ} \mathrm{C}$. In this study, the optimal calcination temperature was set to $1250^{\circ} \mathrm{C}$.

Therefore, for the synthesis of HBC, the temperature was maintained at $850^{\circ} \mathrm{C}$ for 30 minutes for the decarbonation reaction, followed by 60 minutes at $1250^{\circ} \mathrm{C}$ where Hauyne is produced and synthesized through natural cooling within the furnace. Fig. 3 shows the calcination temperature condition. Finally, we have verified the yields of CSA and C2S and the values are the same as in Table 3.

\subsection{Physical Property Experiment Method}

The amount of added $\mathrm{CaSO}_{4}$ was calculated according to the production stoichiometry of ettringite depending on the molar ratios of CSA and $\mathrm{CaSO}_{4}$. Then, through substitution, the experimental mixing ratios were obtained and are shown in Table 4 . The mortar compressive strength experiment was carried out in accordance with the KS L ISO 679

Table 4. Hauyne-Belite Cement Mortar Test Mixing Ratio

\begin{tabular}{cccccc}
\hline & $\begin{array}{c}\mathrm{OPC} \\
\text { (wt.\%) }\end{array}$ & $\begin{array}{c}\mathrm{HC} \\
\text { (wt.\%) }\end{array}$ & $\begin{array}{c}\mathrm{MC} \\
(\text { wt.\%) }\end{array}$ & $\begin{array}{c}\mathrm{LC} \\
\text { (wt.\%) }\end{array}$ & $\begin{array}{c}\mathrm{CaSO}_{4} \\
\text { (wt.\%) }\end{array}$ \\
\hline Plain & 100 & - & - & - & - \\
$\mathrm{HC}$ & - & 64.6 & - & - & 35.4 \\
$\mathrm{MC}$ & - & - & 76.9 & - & 23.1 \\
$\mathrm{LC}$ & - & - & - & 83.3 & 16.7 \\
\hline
\end{tabular}


"cement strength experiment method". Specimens with dimensions of $40 \times 40 \times 160 \mathrm{~mm}$, W/B 0.5, and S/B 3.0 were prepared. The HBC compressive strength was measured for ages of 1, 3, 7 and 28 days. In order to measure the hydration reaction heat, an insulation box was used to measure the simple hydration heat with a 10 point data logger manufactured by Kyowa.

Also, a paste of W/B 0.4 was fabricated to investigate the hydration products of $\mathrm{HBC}$, and after curing at $21^{\circ} \mathrm{C}$ and humidity of $60 \%$, the acetone immersion method was used based on ages of 1, 3, 7 and 28 days to make measurements by XRD (Rigaku. Co., D/Max-2500V) and FE-SEM (JSM6701F/X-Max) after hydration termination. XRD analysis was carried out for the range of 2 theta $5 \sim 65^{\circ}$ at a scan rate of $1 \% \mathrm{~min}$.

\section{Results and Discussion}

\subsection{Simple Hydration Heat Measurement Result}

Figure 4 shows the hydration heat measurement result. Generally, CSA mainly produces ettringite and C-A-H from hydration through reactions of $\mathrm{SO}_{3}, \mathrm{CaO}$, and $\mathrm{H}_{2} \mathrm{O}$. The hydration measurement result showed hydration heat curves of $106.8^{\circ} \mathrm{C}, 103^{\circ} \mathrm{C}$, and $87.3^{\circ} \mathrm{C}$ for $\mathrm{HC}, \mathrm{MC}$, and $\mathrm{MC}$, respectively, and higher reaction heats were measured for greater CSA amounts. This result was determined to be

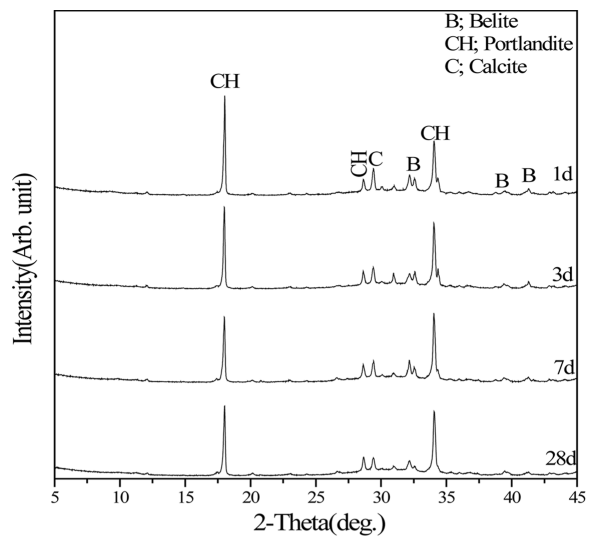

(a) OPC

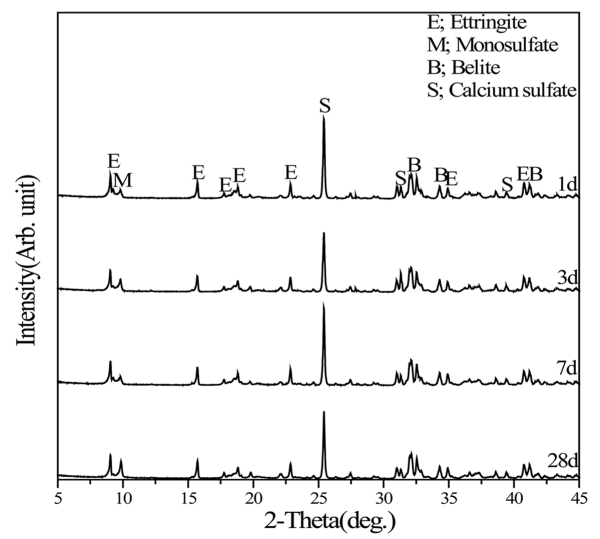

(c) $\mathrm{MC}$

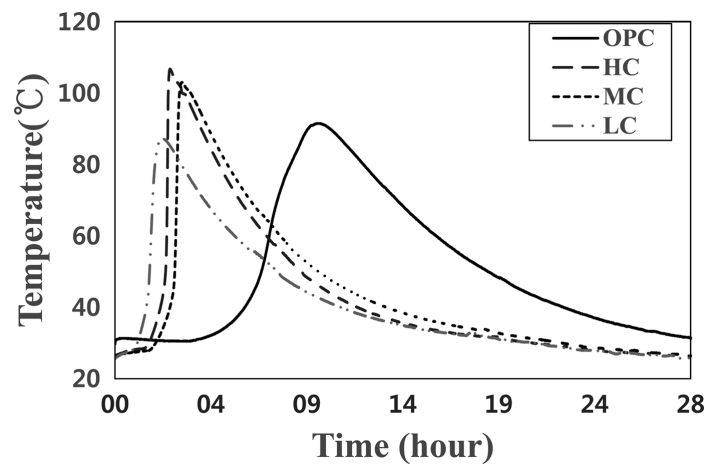

Fig. 4. Heat of hydration of cement paste.

hydration heat due to the ettringite production reaction, and it was concluded that the initial hydration reaction was proportional to the CSA amount. Meanwhile, LC showed the highest reaction rate and a greater amount of stabilized phase $\mathrm{C}_{2} \mathrm{~S}$ compared to CSA. Therefore, the $\mathrm{Ca}$ and $\mathrm{Al}$ ions of CSA were more conveniently released to produce ettringite at a relatively faster time and faster hydration heat rate.

\subsection{XRD Analysis Result of the Hydration Products}

Through the hydration reaction, CSA produces ettringite and C-A-H products, which contribute to the initial strength development. The results of the X-ray diffraction analysis

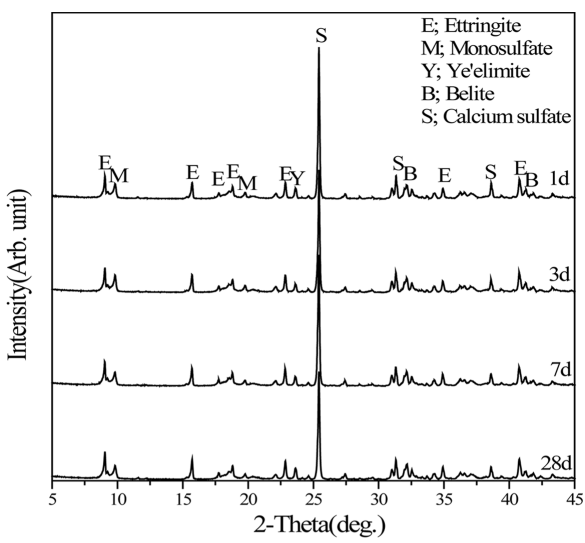

(b) $\mathrm{HC}$

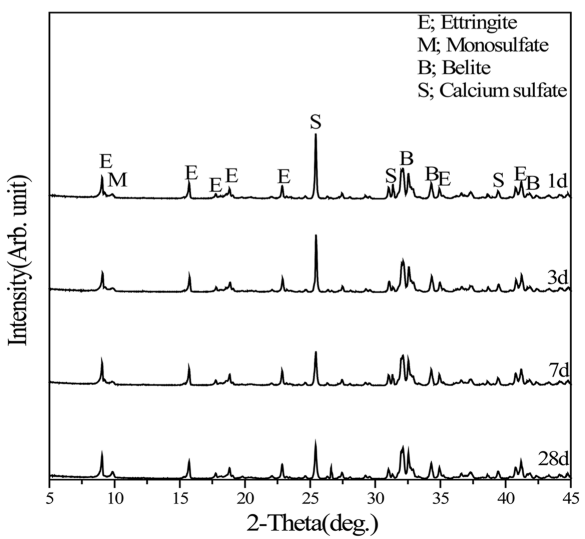

(d) LC

Fig. 5. Results of XRD analysis. 
performed to determine the $\mathrm{HBC}$ hydration products according to curing age are shown in Fig. 5.

For HBC, overall non-hydrated $\mathrm{CaSO}_{4}$ was identified, which was determined to be a result of the gypsum added, according to the theoretical amount of ettringite production, and the amount remaining without participating in the reaction. The amount of gypsum remaining was estimated by the peak intensity. The peak intensity order was $\mathrm{HC}>$ MC > LC, which was thought to be due to the differences in the amounts of gypsum added for each type.

Also, when the ettringite production amount was estimated by peak intensity according to each type and curing age, the ettringite production amount was almost constant regardless of the amount of added gypsum depending on the type and curing age from 1 to 28 days, along with the CSA amount. Here, gypsum was added based on the CSA content for each type according to the stoichiometry of Eq. (1) for ettringite production.

$$
\begin{aligned}
& \mathrm{C}_{4} \mathrm{~A}_{3} \cdot \mathrm{CaSO}_{4}+8 \mathrm{CaSO}_{4} \cdot 2 \mathrm{H}+6 \mathrm{CH}+74 \mathrm{H} \\
& \quad \rightarrow 3\left(\mathrm{C}_{3} \mathrm{~A} \cdot 3 \mathrm{CaSO}_{4} \cdot 32 \mathrm{H}\right)
\end{aligned}
$$

The result obtained was thought to be because the theoretical production rates of ettringite for $\mathrm{HC}, \mathrm{MC}$, and $\mathrm{LC}$ were in similar ranges when the CSA amount and gypsum addition amount for each type were converted to percent- ages.

For OPC, it was found that the alite peak showed a decreasing trend as the curing age increased, and this was thought to contribute to the strength development according to the OPC hydration mechanism, through continuous C-S-H hydrate production.

\subsection{Hydration Product SEM Analysis Result}

Figures 6 and 7 show the SEM analysis results of the hydration products. The SEM image for the curing age of 1 day revealed a high distribution of acicular C-S-H hydrates for OPC, while ettringite was mainly distributed for HBC. For the curing age of 28 days, fine, acicular C-S-H hydrates were observed for OPC. For HBC, ettringite and fine, acicular C-S-H hydrates were observed, but the ettringite was dominantly distributed over the C-S-H hydrates. Therefore, for the curing age of 28 days, C-S-H hydrates were dominant for OPC hydrates, while ettringite was dominant for HBC hydrates.

\subsection{HBC Compressive Strength Results}

Figure 8 shows the compressive strength results for the hardened HBC. The compressive strength measurement results showed that among the gypsum added hardened $\mathrm{HBC}$, the HC exhibited higher strength compared to the

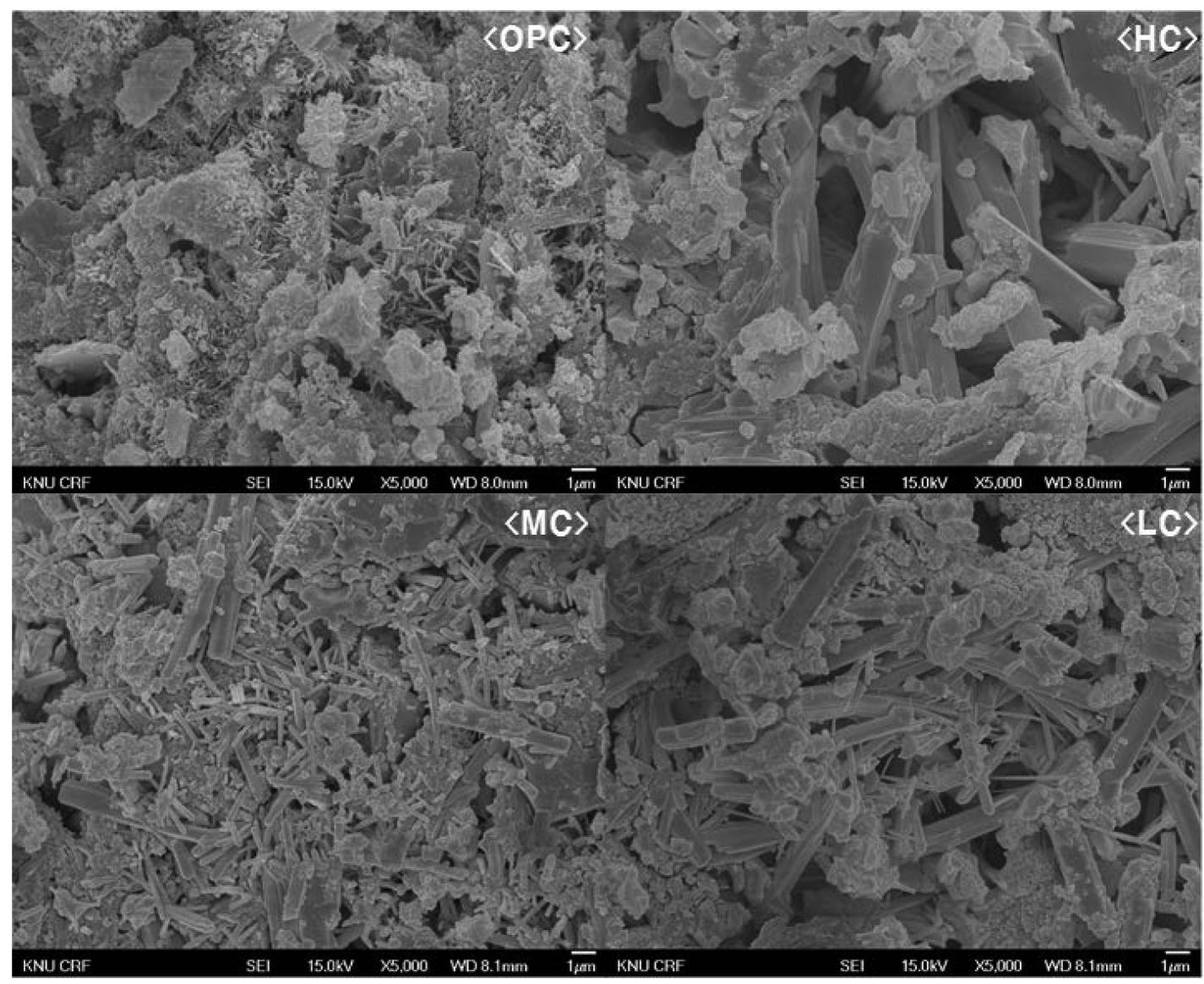

Fig. 6. SEM photo of hydration on day 1. 


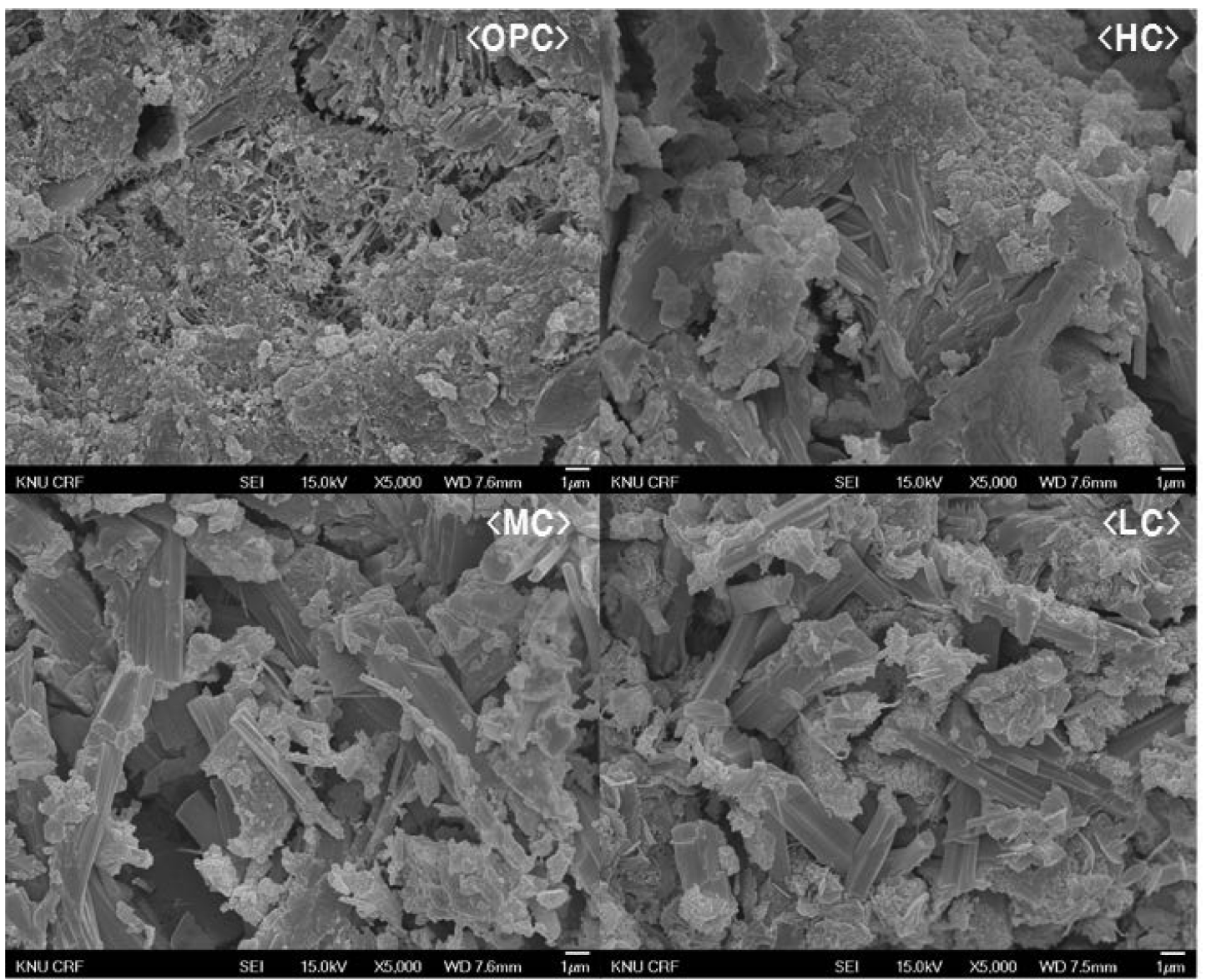

Fig. 7. SEM photo of hydration on day 28.

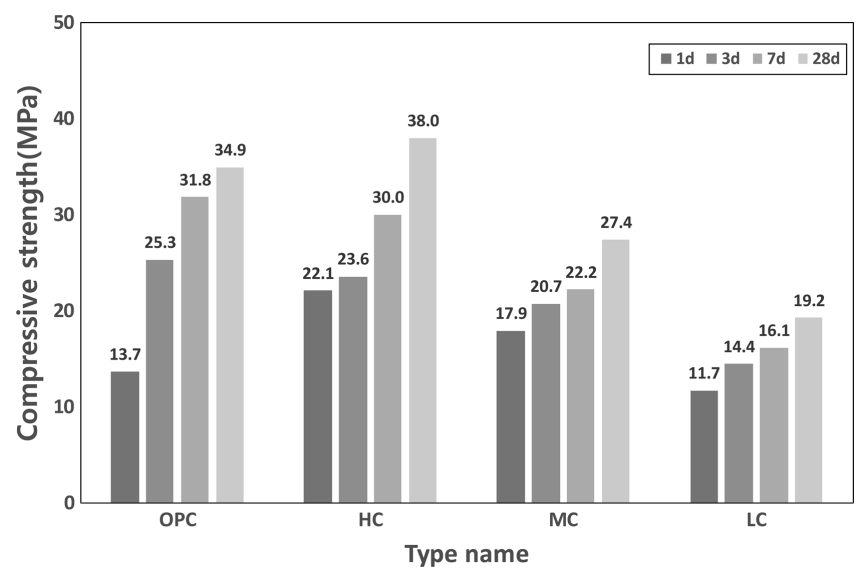

Fig. 8. Compressive strength of mortar by curing age.

hardened OPC, while the hardened MC and LC exhibited lower compressive strength development compared to the hardened OPC. This result signified the initial compressive strength development through the production of ettringite according to the CSA in the initial stages of the hydration reaction. Also, this result showed that as the amount of $\mathrm{C}_{2} \mathrm{~S}$ becomes relatively greater, the compressive strength development decreases.

As observed in the X-ray diffraction analysis results, the amounts of ettringite produced in each type were similar, however, there were differences in the compressive strength development depending on the $\mathrm{C}_{2} \mathrm{~S}$ amount. In this study, HBC was designed under the assumptions that the ettringite production would dominate the compressive strength development in the initial stages of hydration, followed by $\mathrm{C}_{2} \mathrm{~S}$ hydration dominating the compressive strength development in the latter stages of hydration. However, the results obtained through this study revealed that the overall contribution to the compressive strength development was minimal when the $\mathrm{C}_{2} \mathrm{~S}$ amount with regard to the CSA amount was greater than a specific ratio. Therefore, for the compressive strength development of $\mathrm{HBC}$, the ettringite production dominated the compressive strength development for all the hydration curing ages, and it was predicted that the hydration of $\mathrm{C}_{2} \mathrm{~S}$ has an assistive role in the compressive strength development. Further research is necessary to determine the underlying theoretical mechanism.

\section{Conclusions}

In this study, the optimal synthesis conditions and corresponding synthesis yield of Hauyne-Belite Cement were investigated and the following conclusions regarding hydration behavior were obtained. 
1) The yields of CSA and $\mathrm{C}_{2} \mathrm{~S}$ according to the chemical composition ratios were $8: 2,5: 5$, and $3: 7$, and it was found that the optimal calcination temperature of $1250^{\circ} \mathrm{C}$ was appropriate.

2) With regard to the mineral composition of the synthesized HBC, the development of compressive strength was not affected when the $\mathrm{C}_{2} \mathrm{~S}$ amount for the CSA amount was greater than a specific ratio. The model with compressive strength development higher than that of OPC was found in this study to be the $8: 2$ ratio of $\mathrm{CSA}$ and $\mathrm{C}_{2} \mathrm{~S}$.

3) The $\mathrm{HBC}$ with an $8: 2$ ratio of $\mathrm{CSA}$ and $\mathrm{C}_{2} \mathrm{~S}$ showed higher compressive strength than OPC due to the the production of ettringite in the initial stages of hydration. The produced ettringite was found to dominate the compressive strength of all the hydration curing ages.

4) The $\mathrm{HBC}$ with an $8: 2$ ratio of $\mathrm{CSA}$ and $\mathrm{C}_{2} \mathrm{~S}$ showed a greater strength development than OPC with a curing age of 28 days, however, the role of $\mathrm{C}_{2} \mathrm{~S}$ on the enhancement of long-term strength could not be assessed.

\section{REFERENCES}

1. H. J. Song, Effects of Calcium Aluminate Compounds on Hydration of Blast Furnace Slag (in Korean), in Master Thesis, Kangwon National University, Samchuk, 2016.

2. S. H. Lee, Physical and Chemical Properties of Cement Mortar with Gamma-C2S (in Korean), in Master Thesis, Kangwon National University, Samchuk, 2016.

3. K. D. Ki, The Study on Characteristics and Preparation of CSA Using Alunite (in Korean), in Master Thesis, Myungji University, Seoul, 2000.

4. B. Ma, X. Li, Y. Mao, and X. Shen, "Synthesis and Characterization of High Belite Sulfoaluminate Cement through Rich Alumina Fly Ash and Desulfurization Gypsum," Ceram.-Silik., 57 [1] 7-13 (2013).

5. S. H. Lee, Study of the Synthesis of Hauyne-Belite Cement and its sea-Water Resistance (in Korean), in Master Thesis, Myungji University, Seoul, 1984.

6. Irvin Allen Chen, B. S., Synthesis of Portland Cement and Calcium Sulfoaluminate-Belite Cement for Sustainable Development and Performance, in Ph.D. Thesis, The University of Texas at Austin, Austin, 2009.

7. Y. Shen, J. Qian, J. Chai, and Y. Fan, "Calcium Sulphoaluminate Cements Made with Phosphogypsum: Production Issues and Material Properties," Cem. Concr. Compos., 48 67-74 (2014). 